\title{
Survey of Sterile Admixture Practices in Canadian Hospital Pharmacies: Part 2. More Results and Discussion
}

\author{
Travis Warner, Cesilia Nishi, Ryan Checkowski, and Kevin W Hall
}

\begin{abstract}
Background: The 1996 Guidelines for Preparation of Sterile Products in Pharmacies of the Canadian Society of Hospital Pharmacists (CSHP) represent the current standard of practice for sterile compounding in Canada. However, these guidelines are practice recommendations, not enforceable standards. Previous surveys of sterile compounding practices have shown that actual practice deviates markedly from voluntary practice recommendations. In 2004, the United States Pharmacopeia (USP) published its "General Chapter <797> Pharmaceutical Compounding-Sterile Preparations”, which set a more rigorous and enforceable standard for sterile compounding in the United States.
\end{abstract}

Objectives: To assess sterile compounding practices in Canadian hospital pharmacies and to compare them with current CSHP recommendations and USP chapter $<797>$ standards.

Methods: An online survey, based on previous studies of sterile compounding practices, the CSHP guidelines, and the chapter <797> standards, was created and distributed to 193 Canadian hospital pharmacies.

Results: A total of 133 pharmacies completed at least part of the survey, for a response rate of $68.9 \%$. All respondents reported the preparation of sterile products. Various degrees of deviation from the practice recommendations were noted for virtually all areas of the CSHP guidelines and the USP standards. Low levels of compliance were most notable in the areas of facilities and equipment, process validation, and product testing. Availability in the central pharmacy of a clean room facility meeting or exceeding the criteria of International Organization for Standardization (ISO) class 8 is a requirement of the chapter $<797>$ standards, but more than $40 \%$ of responding pharmacies reported that they did not have such a facility. Higher levels of compliance were noted for policies and procedures, garbing requirements, aseptic technique, and handling of hazardous products. The survey methods for this study and results relating to policies, personnel, raw materials, storage and handling, facilities and equipment, and garments were reported in Part 1. Part 2 reports results relating to preparation of aseptic products, expiry dating, labelling, process validation, product testing and release, documentation, records, and disposal of hazardous pharmaceuticals. It also highlights some of the key areas where there is considerable opportunity for improvement.

Conclusion: This survey identified numerous deficiencies in sterile compounding practices in Canadian hospital pharmacies. Awareness of these deficiencies may create an impetus for critical assessment and improvements in practice.

\begin{abstract}
RÉSUMÉ
Contexte : Les Lignes directrices sur la préparation des produits stériles dans les pharmacies de la Société canadienne des pharmaciens d'hôpitaux (SCPH) publiées en 1996 représentent la norme actuelle de pratique en matière de préparation de produits stériles au Canada. En revanche, ces lignes directrices sont des recommandations en matière de pratique et non pas des normes coercitives. Des sondages menés sur la préparation des produits stériles ont révélé une non-observance marquée de ces recommandations de pratique à conformité volontaire. En 2004, la United States Pharmacopeia (USP) publiait son "General Chapter $<797>$ Pharmaceutical Compounding-Sterile Preparations ", qui met de l'avant une norme plus rigoureuse et coercitive en matière de préparation des produits stériles aux États-Unis.
\end{abstract}

Objectifs : Évaluer les pratiques de préparation des produits stériles dans les pharmacies hospitalières canadiennes et les comparer aux recommandations actuelles de la SCPH et aux normes du chapitre $<797>$ de l'USP.

Méthodes : Un sondage en ligne fondé sur des études antérieures des pratiques en matière de préparation des produits stériles, les lignes directrices de la SCPH et les normes du chapitre $<797>$ a été créé et distribué à 193 pharmacies hospitalières au Canada.

Résultats : Un total de 133 pharmacies ont répondu au sondage, soit un taux de réponse de $68,9 \%$. Tous les répondants ont déclaré préparer des produits stériles. Divers degrés de non-observance ont été notés dans presque toutes les sphères des lignes directrices de la $\mathrm{SCPH}$ et des normes de l'USP. Un faible taux d'observance était particulièrement remarquable en matière d'installations et d'équipement, de validation de la procédure et de contrôle des produits. Laccès à une salle blanche de classe 8 ou supérieure selon l'Organisation internationale de normalisation (ISO) dans la pharmacie centrale est une exigence du chapitre $<797>$, mais plus de $40 \%$ des répondants ont déclaré ne pas disposer d'une telle salle. De meilleurs taux d'observance ont été notés au chapitre des politiques et procédures, des vêtements de protection, des techniques aseptiques et de la manipulation des produits dangereux. La première partie de cette série a décrit la méthodologie du sondage et les résultats concernant les politiques, le personnel, les matières premières, l'entreposage et la manipulation, les installations et l'équipement, et les vêtements. La deuxième partie traite des résultats portant sur la préparation des produits aseptiques, l'attribution de la date de péremption, l'étiquetage, la validation de la procédure, le contrôle et la délivrance des produits, les registres, et l'élimination des produits pharmaceutiques dangereux. Elle souligne aussi certains des domaines clés qui méritent une attention considérable. 
Key words: chapter $<797>$, sterile compounding, aseptic technique, expiry dating, process validation, disposal of hazardous pharmaceuticals

Can J Hosp Pharm 2009;62(3):192-203
Conclusion : Ce sondage a mis au jour de nombreuses lacunes dans les pratiques de préparation des produits stériles dans les pharmacies hospitalières au Canada. La sensibilisation à ces lacunes pourrait donner l'élan nécessaire à une évaluation critique et à des améliorations de la pratique.

Mots clés : chapitre <797>, préparation de produits stériles, techniques aseptiques, attribution de la date de péremption, validation de la procédure, élimination des produits pharmaceutiques dangereux

[Traduction par l'éditeur]

\section{INTRODUCTION}

$\mathrm{F}$ or the past decade, the 1996 Guidelines for Preparation of Sterile Products in Pharmacies of the Canadian Society of Hospital Pharmacists (CSHP) ${ }^{1}$ have served as the standard of practice for the preparation of sterile admixtures in Canadian hospital pharmacies. These guidelines provide recommendations that pharmacists and their organizations can use to safely guide sterile compounding practices. The 1996 CSHP guidelines do not constitute a legal or accreditation requirement, and current compliance with the guidelines is unknown.

In January 2004, the United States Pharmacopeia (USP) published the first mandatory, enforceable standards relating to the compounding of sterile preparations in the United States. ${ }^{2}$ These standards are more demanding than recommendations in previous guidelines. A recent study has shown that these new standards are having a significant impact on sterile compounding practices in the United States. ${ }^{3}$

In light of the institution of new standards in the United States and the historically ineffective nature of voluntary guidelines, it is likely that some form of enforceable sterile compounding standards similar to those in the United States will soon be introduced in Canada. The aim of the survey described in this 2-part series (which was conducted in conjunction with the CSHP) was to determine the extent of compliance of Canadian hospital pharmacies with current CSHP and USP chapter $<797>$ standards of practice for the preparation of sterile products. The previous article ${ }^{4}$ provided methodologic details and results for 6 categories of requirements (policies, personnel, raw materials, storage and handling, facilities and equipment, and garments). The current article presents results for 8 additional categories of requirements (preparation of aseptic products, expiry dating, labelling, process validation, product testing and release, documentation, records, and disposal of hazardous pharmaceuticals) and a discussion of the implications of the findings, with suggestions for improving compliance in several high-priority areas.

The survey to assess compliance with sterile compounding practices in Canada was based on the CSHP guidelines, ${ }^{1}$ USP chapter $<797>,^{2}$ guidelines of the American Society of Health-System Pharmacists (ASHP), ${ }^{5,6}$ and the ASHP self- assessment tool ${ }^{7}$ for determining compliance with USP chapter $<797>$. The survey was field-tested, updated, pilot-tested, and updated again. The final version of the survey was formatted within online survey software (SurveyMonkey.com, Portland, Oregon). A request to participate in the survey was sent to hospital pharmacy managers practising in all Canadian acute care hospitals with at least 50 acute care beds and at least 100 beds in total (both acute and non-acute care). Survey responses were recorded and tabulated automatically by the survey software, which also assembled descriptive statistics. Complete details of the survey methods are available in part 1 of this series. ${ }^{4}$

\section{RESULTS}

The characteristics of the hospitals represented by the respondents, as well as the survey results related to policies, personnel, raw materials, storage and handling, facilities and equipment, and garments, can be found in part 1 of this series. ${ }^{4}$ Survey results for the preparation of aseptic products, expiry dating, labelling, process validation, product testing and release, documentation, records, and disposal of hazardous pharmaceuticals are presented here.

\section{Comparison of Survey Results with 1996 CSHP Guidelines and USP Chapter <797>}

\section{Policies, Procedures, and Techniques for Preparation of Aseptic Products}

\section{Summary of CSHP Guidelines and USP Chapter <797>}

The CSHP and USP recommendations regarding aseptic preparation policies and procedures are summarized in Table 1. Both organizations recommend that all sterile products be prepared under aseptic conditions (i.e., within a Federal Standard 209E class $100^{8}$ [International Organization for Standardization or ISO class $5^{\circ}$ ] laminar airflow hood or biological safety cabinet), unless they are to be used immediately. Items not prepared under aseptic conditions and not administered immediately are to be discarded. Recommendations related to proper aseptic technique are summarized in Table 2. 
Table 1. Policies and Procedures for Preparation of Aseptic Products

Hospital Area; No. (\%) Reporting Requirement

\begin{tabular}{lcccccc} 
Policy or Procedure* & \multicolumn{2}{c}{$\begin{array}{c}\text { Central Pharmacy } \\
(\boldsymbol{n}=\mathbf{1 0 2})\end{array}$} & $\begin{array}{c}\text { IV Prep Areas (Oncology) } \\
(\boldsymbol{n}=\mathbf{8 7})\end{array}$ & $\begin{array}{c}\text { Satellite Pharmacy } \\
(\boldsymbol{n}=\mathbf{1 3})\end{array}$ \\
\hline No eating or drinking & 98 & $(96.1)$ & 84 & $(96.6)$ & 10 & $(77)$ \\
No storage of food or personal items & 96 & $(94.1)$ & 84 & $(96.6)$ & 9 & $(69)$ \\
Handwashing before starting work inside the hood & 100 & $(98.0)$ & 83 & $(95.4)$ & 12 & $(92)$ \\
Handwashing on re-entry into aseptic preparation area & 82 & $(80.4)$ & 67 & $(77.0)$ & 9 & $(69)$ \\
Handwashing with suitable antimicrobial cleanser & & & & & & \\
for at least 10-15 s & 93 & $(91.2)$ & 80 & $(92.0)$ & 10 & $(77)$ \\
Handwashing with disposable scrub brush & 39 & $(38.2)$ & 32 & $(36.8)$ & 4 & $(31)$ \\
Handwashing up to elbow with suitable & 73 & $(71.6)$ & 62 & $(71.3)$ & 9 & $(69)$ \\
antimicrobial cleanser & 87 & $(85.3)$ & 75 & $(86.2)$ & 8 & $(62)$ \\
Hand-drying with air-dryer or one-time use towelst & 70 & $(68.6)$ & 62 & $(71.3)$ & 7 & $(54)$ \\
Restriction on personnel permitted to the areat & & & &
\end{tabular}

*Included in guidelines of the Canadian Society of Hospital Pharmacists, ${ }^{1}$ except where indicated otherwise.

tIncluded in United States Pharmacopeia chapter $<797>{ }^{2}$

\section{Table 2. Aseptic Technique}

Technique*

No. (\%) of respondents

Items checked for defects, damage, and expiry dates before use

$(n=104)$

Items checked by Drug Identification Number (DIN) for product identification

$102 \quad(98.1)$

All nonsterile surfaces disinfected with alcohol or a suitable antimicrobial agent before being placed in hood

All materials needed for processing placed in hood before sterile products are prepared

All processing done at least $15 \mathrm{~cm}$ from edge of hood

$27 \quad(26.0)$

When in hood, materials and activities are arranged so as not to interrupt airflow between the

HEPA filter and items within the hood

ciling air vents) are situated so as not to interrupt aiflow in

Only one person allowed to work in laminar airflow hood at one time

Personnel avoid making direct contact with critical surfaces or nonsterile products and surfaces 102

When in hood, nonsterile critical surfaces are disinfected before being punctured

HEPA = high-efficiency particulate air.

*Included in guidelines of the Canadian Society of Hospital Pharmacists, ${ }^{1}$ except where indicated otherwise.

†Not mentioned in either the guidelines of the Canadian Society of Hospital Pharmacists ${ }^{1}$ or United States Pharmacopeia

chapter $<797>$. $^{2}$

\section{Table 3. Inspection of Drug Storage Areas External to the Pharmacy}

Frequency of Inspection; No. (\%) of Respondents

\begin{tabular}{|c|c|c|c|c|c|c|c|c|c|c|}
\hline \multirow{3}{*}{$\begin{array}{l}\text { Items inspected* } \\
\text { Compliance with appropriate } \\
\text { storage conditions }(n=96)\end{array}$} & \multirow{2}{*}{\multicolumn{2}{|c|}{ Daily }} & & & \multirow{2}{*}{\multicolumn{2}{|c|}{ Monthly }} & & & & \\
\hline & & & \multicolumn{2}{|c|}{ Weekly } & & & \multicolumn{2}{|c|}{ > Monthly } & \multicolumn{2}{|c|}{ Not checked } \\
\hline & 49 & $(51.0)$ & 9 & $(9.4)$ & 4 & $(4.2)$ & 12 & (12.5) & 22 & (22.9) \\
\hline $\begin{array}{l}\text { Proper use of multiple-dose } \\
\text { containers }(n=97)\end{array}$ & 16 & (16.5) & 21 & (21.6) & 8 & (8.2) & 14 & (14.4) & 38 & (39.2) \\
\hline $\begin{array}{l}\text { Drugs appropriately separated } \\
\text { from food }(n=97)\end{array}$ & 36 & (37.1) & 14 & (14.4) & 5 & $(5.2)$ & 16 & (16.5) & 26 & $(26.8)$ \\
\hline $\begin{array}{l}\text { Single-dose products not being } \\
\text { used as multiple-dose products } \\
(n=97)\end{array}$ & 15 & (15.5) & 12 & (12.4) & 4 & (4.1) & 11 & (11.3) & 55 & $(56.7)$ \\
\hline
\end{tabular}

*Included in United States Pharmacopeia chapter $<797>{ }^{2}$

\section{Survey Results}

The responses regarding aseptic compounding policies and procedures were nearly identical in frequency for central pharmacy and oncology IV preparation areas (Table 1), with nearly all respondents reporting the existence of policies or procedures related to eating and drinking, food storage, hand- washing (before starting work, and for an appropriate length of time), and hand-drying by appropriate means. Slightly fewer respondents indicated that policies and procedures were in place requiring handwashing upon re-entry into the aseptic preparation area. Roughly two-thirds of sites had policies and procedures relating to handwashing up to the elbow with a suitable antimicrobial cleanser and restrictions on the personnel 
permitted in the aseptic preparation area. Roughly one-third of sites had policies or procedures on the use of scrub brushes for handwashing. For satellite pharmacies, the reported prevalence of all of these policies and procedures was slightly lower.

A very high level of compliance was noted for 6 of the 10 of the practices listed in Table 2. Compliance was slightly lower for recommendations relating to disinfection of nonsterile surfaces, placement of external airflow control devices (e.g., ceiling air vents) in the aseptic preparation area, and restrictions on the number of individuals allowed to work in a laminar airflow hood at one time. Use of a product's Drug Identification Number (DIN) to verify identification of a product before use was reported by only 27 (26.0\%) of 104 respondents. This practice is not a USP or CSHP recommendation but was included in the survey on the basis of feedback received during survey design and pilot-testing. However, use of a DIN to verify product identity may not be appropriate, given that different-sized vials or bags of a solution or medication may have the same DIN; as such, the DIN may not be a unique identifier.

\section{Expiry Dating (Beyond-Use Dating)}

\section{Summary of CSHP Guidelines and USP Chapter <797>}

The CSHP guidelines state that expiration dating should be determined separately for each type of product, on the basis of information from sources such as manufacturers' recommendations, pharmaceutical compendia, published literature, and in-house testing. For products without sterility data, USP chapter $<797>$ specifies expiry dating on the basis of risk level, as summarized in Appendix 1., ${ }^{20}$ Multiple-dose vials lacking specific beyond-use dating recommendations are to be refrigerated, if appropriate, and are to be arbitrarily assigned a 30-day beyond-use date following initial use. Chapter <797> also requires policies to ensure that expired sterile products are returned to the pharmacy for proper disposal. Furthermore, it requires that the conditions for storing sterile products on the wards, as listed in Table 3, be checked monthly, to ensure that these products are stored appropriately after they leave the pharmacy.

\section{Survey Results}

All respondents indicated that expiry dates were assigned to sterile products prepared in their pharmacies. Published references were the most commonly cited source for expiry dates, followed by manufacturers' recommendations, results of published or unpublished stability tests done at other facilities, comparison with similar products, and results of on-site stability testing. Small numbers of respondents reported using USP chapter <797> standards, regional guidelines, or arbitrarily determined dates.

For products involving a single transfer of sterile drug from an ampoule, bottle, bag, or vial to a final container, the major- ity of respondents reported an assigned expiry period of 24-48 $\mathrm{h}$ if stored at room temperature, 8-45 days if stored in the refrigerator, and more than 45 days if stored in a solid frozen state. For 3 categories of total parenteral nutrition preparations (those containing 3 or fewer sterile additives, those containing more than 3 sterile additives, and those prepared with an automated compounding device), the majority of respondents indicated expiry dating of 24-48 h if stored at room temperature or with refrigeration; no respondents reported storing these products in a solid frozen state. For products involving multiple transfers of sterile drug from vials to final containers, the majority of respondents reported an assigned expiry period of less than $24 \mathrm{~h}$ if stored at room temperature, 8-45 days if stored in the refrigerator, and more than 45 days if stored in a solid frozen state. Sterile products prepared from nonsterile ingredients were assigned expiry periods of less than $24 \mathrm{~h}$ if stored at room temperature or with refrigeration. Very few respondents reported storing such products in a frozen state. Total parenteral nutrition solutions containing a lipid emulsion were assigned an expiry period of $12-24$ h by 14 (14.7\%) of 95 respondents; $3(3.2 \%)$ of 95 respondents assigned an expiry period of longer than $24 \mathrm{~h}$, and the remainder indicated that their sites did not prepare this type of product.

Sixty-one $(61.6 \%)$ of 99 respondents reported that singleuse vials and ampoules were discarded immediately after use, whereas 32 (32.3\%) reported that such vials and ampoules were discarded after $24 \mathrm{~h}$. A small number of respondents reported retaining these products for longer periods at room temperature or with refrigeration. The majority of respondents $(65 / 99$ or $65.7 \%$ ) reported discarding multiple-use vials after 2-29 days if stored in a refrigerator. Few respondents reported keeping multiple-dose vials at room temperature; of those who did, the majority $(25 / 27$ or $93 \%)$ reported discarding the vials within 2-29 days of initial use. Seventeen (17.2\%) of 99 respondents reported that multiple-use vials were discarded only after the manufacturer's expiry date.

Compliance with recommendations for proper storage conditions for sterile products on patient care wards was only marginal (Table 3). A substantial level of noncompliance was noted with regard to surveillance of use of multiple-dose containers, proper separation of drug products from food, and avoidance of the practice of using single-use products as multiple-use products.

\section{Labelling \\ Summary of CSHP Guidelines and USP Chapter <797>}

The CSHP guidelines state that labels for sterile products should include the information listed in Tables 4 and 5. USP $<797>$ includes labelling standards similar to those described by the CSHP. Compounded sterile products must be properly labelled with names and amounts or concentrations of all ingredients, total volume, beyond-use date, appropriate 
route(s) of administration, storage conditions and other information for safe use. The CSHP guidelines state that a pharmacist or delegate must check each label against the original order or master worksheet before the product is released.

\section{Survey Results}

All or most respondents reported that labels for patientspecific products included information on patient name and location, generic ingredients, quantity or concentration of ingredients, and expiry dates (Table 4). Somewhat fewer sites included the reference number of the original prescription or medication order, vehicle names, prescribed administration regimen, auxiliary labels, or storage requirements on these labels. Slightly more than two-thirds of sites included the date of preparation on patient-specific product labels, roughly half identified the pharmacy personnel involved in product preparation and dispensing, slightly fewer than half included a control or lot number, and roughly one-third included device-specific instructions (e.g., for use with patient-controlled analgesia devices).
For batch products, nearly all respondents reported that the label included a control or lot number, generic ingredients, quantity or concentration of ingredients, and expiry dating (Table 4). Sixty-nine $(79.3 \%)$ of 87 respondents reported that labels included storage requirements, and $76(87.4 \%)$ reported that labels included vehicle names. Roughly two-thirds of respondents reported the inclusion of the date of preparation on the label, and 49 (56.3\%) of 87 respondents reported that auxiliary labels were used. Fewer than half of the respondents reported that staff members involved in the preparation of batch products were identified on product labels. Few respondents reported the inclusion of information on administration regimen, devicespecific instructions, a reference number for the prescription or medication order, or a patient's name and location on labels, but some of these items may not be applicable to batch products.

For outpatient products dispensed from the hospital's dispensary, 45 (98\%) of 46 respondents reported including the name, address, and phone number of the pharmacy on product labels (Table 5). Ten respondents (22\%) reported including disposal instructions, and 6 (13\%) included written instructions on how to safely open containers.

\section{Table 4. Labelling Information for Products Prepared for Inpatients}

Information*

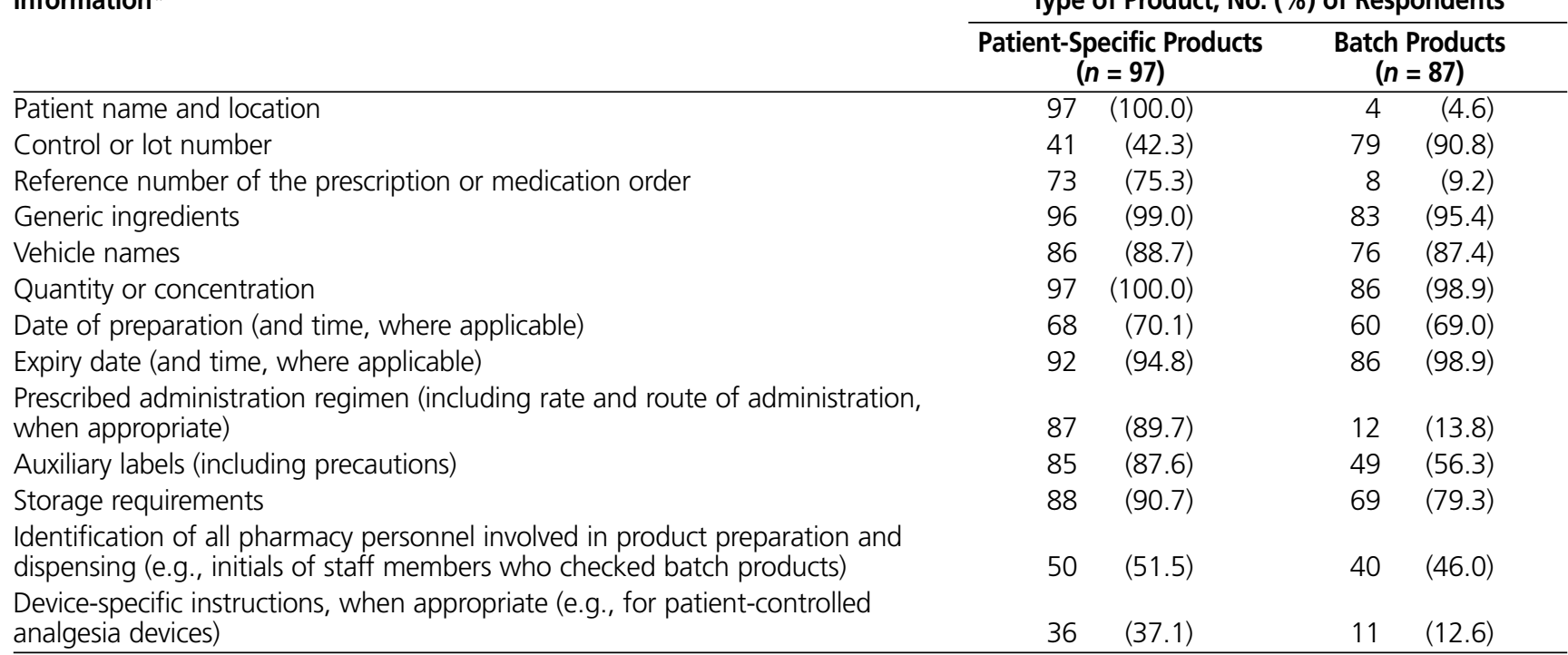

*Included in guidelines of the Canadian Society of Hospital Pharmacists.

Table 5. Labelling Information for Products Prepared for Outpatients

\begin{tabular}{lrr} 
Information* & $\begin{array}{r}\text { No. (\%) of Respondents } \\
(\boldsymbol{n}=\mathbf{4 6})\end{array}$ \\
\hline Name, address, and phone number of the pharmacy & 45 & $(98)$ \\
Disposal instructionst & 10 & $(22)$ \\
Written instructions on how to safely open containerst & 6 & $(13)$ \\
\hline *Included in guidelines of the Canadian Society of Hospital Pharmacists, & & \\
except where indicated otherwise. & \\
tIncluded in United States Pharmacopeia chapter $<797>.^{2}$
\end{tabular}


Seventy-five $(78.9 \%)$ of 95 respondents reported that pharmacists were involved in checking product labels against the original order or a pharmacist-verified copy. Fifty (60.2\%) of 83 respondents indicated that technicians were involved in checking product labels.

\section{Process Validation \\ Summary of CSHP Guidelines and USP Chapter <797>}

Process validation procedures ensure that the sterility and composition of a finished product meet expectations for that product. The CSHP recommends process validation procedures such as the calibration and monitoring of equipment, validation of aseptic technique, environmental monitoring, and documentation of processes for preparing sterile products. Laminar airflow hoods should be recertified annually and upon relocation; automated compounding devices should be calibrated and certified, if possible; the temperature of refrigerators and freezers used to store sterile preparations should be monitored regularly; and the integrity of filters used for sterilization should be tested. The CSHP also recommends the use of scientifically sound environmental monitoring processes. USP chapter <797> goes further, requiring that all laminar airflow hoods and biological safety cabinets be certified semiannually and following any relocation of the equipment. Refrigerator, freezer, and incubator temperatures must be checked daily, and equipment such as automated compounding devices should be calibrated according to the manufacturer's recommendations at a frequency specified in written procedures. Additional tests for the accuracy of these devices, such as analytical measurements, density measurements, or measurement of the refractive indices of products, should be employed as well.

\section{Survey Results}

Eighty (81.6\%) of 98 respondents indicated that personnel at their facilities checked refrigerator and freezer temperatures daily. Ten (10.2\%) respondents reported checking temperatures weekly, 1 (1.0\%) reported monthly checks, and $2(2.0 \%)$ reported checks less frequently than monthly. Five $(5.1 \%)$ did not check temperatures at all. Of the 58 respondents who reported on the calibration of automated compounding devices, 35 (60\%) reported daily calibration, 5 (9\%) reported weekly calibration, and $3(5 \%)$ reported monthly calibration. Five respondents (9\%) reported calibrating automated compounding devices less frequently than every month, and $10(17 \%)$ reported that they did not calibrate these devices. Unfortunately, it was unclear how many of the latter respondents actually used automated compounding devices at their facilities; it is possible that many of those who reported not calibrating automated compounding devices did not even have such devices. Accuracy certification of automated compounding devices was reported to take place on a daily basis at $7(14.0 \%)$ of the 50 sites for which this procedure was reported. Two respondents (4.0\%) reported certifying automated compounding devices weekly, 1 (2.0\%) monthly, and $13(26.0 \%)$ less frequently than monthly. Twenty-seven $(54.0 \%)$ of the respondents to this question reported that they did not conduct accuracy certification of automated compounding devices, but again, it was not clear how many of these respondents actually possessed such devices.

Only $7(10.0 \%)$ of 70 respondents reported daily testing of the integrity of filters after use for sterilization, through forward flow, bubble point, or pressure hold tests. One respondent (1.4\%) reported weekly testing, 1 (1.4\%) reported monthly testing, $21(30.0 \%)$ reported less frequently than monthly testing, and $40(57.1 \%)$ reported that the integrity of filters was not checked after use for sterilization.

Nineteen respondents reported using automated compounding devices to prepare products for total parenteral nutrition. Of these, $5(26 \%)$ indicated that their facilities conducted additional tests of accuracy, such as measurements of dextrose, calcium gluconate, magnesium sulphate, or potassium chloride, density measurements, or measurements of refractive index, to determine the content of certain ingredients in the final volume of the parenteral nutrition solution, as required by chapter $<797>$.

Twenty-five respondents reported that their facilities monitored the environment in the sterile preparation area for particulates and microorganisms. Of these, 21 (84\%) reported using surface monitoring with contact plates, swab rinse technique, or other methods; 14 (56\%) reported using air samples taken in aseptic preparation areas; 11 (44\%) reported using warning systems to detect changes in air pressure or air flow; and $3(12 \%)$ reported using centrifugal air-sampling techniques. One site engaged an outside contractor to carry out environmental monitoring. Air quality in the clean room or anteroom, not including hood testing and recertification, was not evaluated by 57 (59.4\%) of 96 respondents. Seven (7.3\%) reported semiannual evaluations, 13 (13.5\%) reported annual evaluations, and $14(14.6 \%)$ reported evaluations less frequently than annually. Four (4.2\%) of the people who responded to this question worked in facilities that did not have a clean room or anteroom, and a single respondent reported that air quality in the clean room or anteroom was tested only when the hood was tested.

All respondents reported that their laminar airflow hoods were recertified either annually or semiannually: Fifty-three (53.0\%) of 100 respondents had annual recertification, in accordance with CSHP recommendations, and 47 (47.0\%) had semiannual recertification, in accordance with chapter $<797>$ standards. All but one of the respondents indicated that laminar airflow hoods were recertified following relocation or that their laminar airflow hoods had never been relocated. 


\section{Product Testing and Release Summary of CSHP Guidelines and USP Chapter <797>}

The CSHP guidelines state that written specifications, with acceptance criteria, should be developed for the testing of all sterile products. Depending on the type of product, inprocess observation and visual inspection and/or sterility testing of the end product are recommended. Products that fail testing are to be destroyed or reprocessed. USP chapter $<797>$ requires testing of the sterility, pyrogenicity, and potency of high-risk products before release.

\section{Survey Results}

In-process observation (e.g., vial and ampoule counts, syringe pull-backs) was reported by $60(61.2 \%)$ of 98 respondents, and random in-process sterility testing was reported by $15(15.3 \%)$ of respondents. Two respondents reported the use of nonrandom in-process sterility testing, and one respondent reported weighing IV bags before and after compounding.

Visual inspection of end products for particulates, clarity, colour, solution volume, leaks, and container integrity was reported by $74(74.7 \%)$ of 99 respondents. Pyrogenicity testing and laboratory verification of ingredient identity and concentrations were reported by only $6(6.1 \%)$ and $2(2.0 \%)$ respondents, respectively. Sterility testing was reported by $19(19.2 \%)$ respondents, and no end-product testing was reported by $22(22.2 \%)$ of respondents. One respondent reported the use of laboratory testing only if there was a "discrepancy". Of the 19 respondents who reported sterility testing, 7 (37\%) reported quarantining some or all batch products pending the results of such tests; 3 of these respondents (16\% of the total) reported quarantining all batch products pending the results of sterility tests. Four respondents (21\%) reported quarantining only products that did not contain a suitable preservative. The remaining respondents reported that they did not quarantine batch products pending the results of sterility tests.

For end products that failed testing, 49 (94\%) of 52 respondents indicated that the offending product would be destroyed. A total of 8 respondents (15\%) reported that a product might be reprocessed and subjected to further testing rather than being destroyed. Three respondents (6\%) reported that failing products were always subjected to further testing rather than being automatically destroyed.

\section{Documentation of Processes Summary of CSHP Guidelines and USP Chapter <797>}

The CSHP recommends that documentation of processes occur as part of process validation. For all batch products, the items listed in Table 6 are to be recorded on a standardized worksheet. USP <797> includes an explicit requirement for documentation of daily checks of refrigerator, freezer, and incubator temperatures and states that there must be a systematic program for quality assessment and improvement, including monitoring, evaluation, and improvement of all activities associated with compounded sterile products. Documentation of all or most of the items listed in Table 6 would likely be required to fulfill these requirements.

\section{Survey Results}

All or nearly all of the respondents reported that the following information was documented for each batch product prepared in their facilities: name and strength of the ingredients, quantity of each ingredient, lot numbers of ingredients, date of preparation, expiry date of the end product, and identity of all personnel involved in preparing the product (Table 6). Between $70 \%$ and $90 \%$ of respondents reported documentation of the manufacturer or supplier of each ingredient, container specifications and lot numbers, endproduct lot number, preparation procedures, end-product name or code (for multiple-ingredient products), storage requirements, and a label sample for each batch product produced. Roughly one-third of respondents reported documenting the equipment used during product preparation, and slightly more than one-quarter each documented DINs and a comparison of actual to anticipated yield. Only 13.0\% reported documenting specifications and results of end-product testing.

\section{Retention of Records Summary of CSHP Guidelines and USP Chapter <797>}

The CSHP guidelines state that records pertaining to the items listed in Table 7 should be kept for at least 1 year after the expiration of a product, unless otherwise specified by provincial or federal law. Some provinces specify that certain documents must be retained for a minimum of 2 years.

\section{Survey Results}

About three-quarters of respondents reported keeping records of original prescriptions and associated documentation, worksheets for batch products, and documentation of equipment assembly, calibration, and certification for 2 years or more (Table 7). Roughly two-thirds of sites retained documents relating to personnel matters, suspected adverse drug reactions related to sterile products, and post-process errors (identified after dispensing) involving sterile products for 2 years or more. Roughly half of the respondents reported a retention period of 2 years or more for data derived from process validation and end-product testing; documentation of cleaning, sanitation, and environmental monitoring; records of refrigerator and freezer checks; records of complaints, recalls and returns; and documentation for in-process errors involving sterile products. 
Table 6. Documentation for Batch Products

\begin{tabular}{lcc} 
Information Documented * & $\begin{array}{r}\text { No. (\%) of Respondents } \\
\text { ( } \boldsymbol{n = 9 2 )}\end{array}$ \\
\hline Ingredient name and strength & 92 & $(100.0)$ \\
Ingredient quantity & 89 & $(96.7)$ \\
Ingredient lot number & 86 & $(93.5)$ \\
Ingredient manufacturer or supplier & 72 & $(78.3)$ \\
Container specifications and lot numbers & 69 & $(75.0)$ \\
Drug Identification Number (DIN)t & 25 & $(27.2)$ \\
Preparation procedures & 64 & $(69.6)$ \\
Equipment used during preparation & 33 & $(35.9)$ \\
Comparison of actual to anticipated yield & 22 & $(23.9)$ \\
Date of preparation & 91 & $(98.9)$ \\
End-product lot number & 75 & $(81.5)$ \\
End-product expiry date & 91 & $(98.9)$ \\
End-product name or code (i.e., for multiple-ingredient products) & 67 & $(72.8)$ \\
Identity of all personnel involved in preparation and release & 87 & $(94.6)$ \\
End-product testing specifications and results & 12 & $(13.0)$ \\
Storage requirements & 74 & $(80.4)$ \\
Label sample & 73 & $(79.3)$ \\
\hline${ }^{*}$ Included in guidelines of the Canadian Society of Hospital Pharmacists. ${ }^{1}$ & & \\
tNot mentioned in either the guidelines of the Canadian Society of Hospital Pharmacists ${ }^{1}$ or \\
United States Pharmacopeia chapter <797>. ${ }^{2}$ & &
\end{tabular}

\section{Table 7. Retention of Records}

Retention Period; No. (\%) of Respondents

\begin{tabular}{|c|c|c|c|c|c|c|c|}
\hline Type of Record* & No. of respondents & & Kept & Kep & $<<2 \mathrm{yr}$ & Kep & $\geq 2 \mathrm{yr}$ \\
\hline Personnel matters, including training and certification & 94 & 20 & $(21.3)$ & 11 & $(11.7)$ & 63 & $(67.0)$ \\
\hline Original prescriptions and associated documentation & 97 & 7 & $(7.2)$ & 16 & $(16.5)$ & 74 & $(76.3)$ \\
\hline Worksheets for batch products & 91 & 3 & $(3.3)$ & 15 & (16.5) & 73 & $(80.2)$ \\
\hline $\begin{array}{l}\text { Data derived from all tests used for process verification } \\
\text { and end-product testing }\end{array}$ & 73 & 30 & $(41.1)$ & 9 & $(12.3)$ & 34 & $(46.6)$ \\
\hline $\begin{array}{l}\text { Documentation of equipment assembly, calibration, } \\
\text { and certification }\end{array}$ & 89 & 19 & $(21.3)$ & 4 & $(4.5)$ & 66 & $(74.2)$ \\
\hline $\begin{array}{l}\text { Documentation of cleaning, sanitation, } \\
\text { and environmental monitoring }\end{array}$ & 86 & 34 & $(39.5)$ & 14 & $(16.3)$ & 38 & $(44.2)$ \\
\hline Records of refrigerator and freezer temperature checkst & 96 & 23 & $(24.0)$ & 29 & $(30.2)$ & 44 & $(45.8)$ \\
\hline Documentation of complaints, recalls, and returns & 94 & 29 & (30.9) & 17 & $(18.1)$ & 48 & $(51.1)$ \\
\hline $\begin{array}{l}\text { Documentation of suspected adverse drug reactions } \\
\text { related to sterile productst }\end{array}$ & 87 & 26 & (29.9) & 8 & $(9.2)$ & 53 & $(60.9)$ \\
\hline Documentation of errors involving sterile products† & & & & & & & \\
\hline In-process errors & 92 & 36 & $(39.1)$ & 11 & $(12.0)$ & 45 & $(48.9)$ \\
\hline Post-process errors (identified after dispensing) & 89 & 20 & $(22.5)$ & 10 & $(11.2)$ & 59 & $(66.3)$ \\
\hline Other & 5 & 3 & $(60.0)$ & 0 & $(0.0)$ & 2 & $(40.0)$ \\
\hline
\end{tabular}

* Included in guidelines of the Canadian Society of Hospital Pharmacists, ${ }^{1}$ except where indicated otherwise. tIncluded in United States Pharmacopeia chapter $<797>$. 2

\section{Handling and Disposal of Hazardous Pharmaceuticals \\ Summary of CSHP Guidelines and USP Chapter <797>}

The handling and disposal of hazardous drugs is addressed in the 1997 CSHP Guidelines for Handling and Disposal of Hazardous Pharmaceuticals (Including Cytotoxic Drugs), ${ }^{11}$ as well as in USP chapter $<797>$. Both organizations recommend that policies and procedures be available regarding the safe handling of hazardous drugs to prevent contamination of the workplace and to protect anyone who might come into contact with hazardous drug products. Chapter $<797>$ also recommends ready availability of guidelines for the safe preparation and administration of antineoplastic drugs. Both recommend that pharmacy personnel be trained, oriented, and competent in the preparation of hazardous drugs, as well as in the 
procedures to be followed in case of accidental exposure to hazardous products. CSHP recommends that personnel wear protective gowns, gloves, eye protection, and, in the absence of a biological safety cabinet, respiratory protection. USP chapter $<797>$ recommends the use of protective gowns, eye protection, masks, hair covers, and 2 pairs of gloves, with the outer pair covering the gown's cuff. Hazardous drugs are to be prepared in class II or III biological safety cabinets or barrier isolators. Furthermore, hazardous products must be labelled as such, with indications of special handling and disposal requirements, and appropriate safeguards must be in place for transport of such products outside the pharmacy.

\section{Survey Results}

Ninety $(92.8 \%)$ of 97 respondents reported the existence of procedures for the appropriate handling of hazardous substances, such as caustic, cytotoxic, or potentially infectious products or radiopharmaceuticals. Ninety-one (92.9\%) of 98 respondents reported guidelines for reconstituting, diluting, and preparing commonly used antineoplastic drugs. Ninetythree $(95.9 \%)$ of 97 respondents indicated that all staff who prepare hazardous drugs at their facilities were appropriately oriented and trained in the accurate and safe preparation of such products. The proportion of respondents who reported a requirement that personnel preparing hazardous drugs wear protective coveralls or gowns (with elastic or knit cuffs) was $96.9 \%$ (93/96). One pair of gloves was required by $18.8 \%$ of sites (18/96); 2 pairs of gloves, with the outer glove not covering the gown's cuff, were required by $4.2 \%$ of sites (4/96); and 2 pairs of gloves, with the outer glove covering the gown's cuff, were required by $77.1 \%$ of sites (74/96). Masks were cited as a requirement by $79.2 \%$ of respondents (76/96), eye protection by $38.5 \%$ (37/96), and hair covers by $82.3 \%$ (79/96). A total of $8(8.3 \%)$ of 96 respondents reported a requirement for foot coverings, and 1 respondent reported the use of respirator masks for cleaning biological safety cabinets and for cleaning up spills.

The equipment most commonly reported (by 81 [84.4\%] of 96 respondents) for use in preparing hazardous products was a class II or III biological safety cabinet. Twenty (20.8\%) of 96 respondents reported that their facilities used vertical airflow hoods, 1 (1.0\%) reported horizontal airflow hoods, $10(10.4 \%)$ reported a clean surface (e.g., countertop), and $2(2.1 \%)$ reported a barrier isolator.

Ninety-three $(96.9 \%)$ of 96 respondents stated that all staff who prepared hazardous products in their facilities were knowledgeable about the proper procedures to follow in case of accidental contact of these products with the skin or the eyes. A total of $80.4 \%$ of respondents (78/97) reported that hazardous drugs prepared at their facilities had warning labels indicating the need for special handling and disposal precautions. Virtually all respondents (95/96 or 99.0\%) indicated that when hazardous drugs were transported outside of the pharmacy, proper safeguards, such as sealed plastic bags or cautionary labelling, were required. A total of $88.7 \%$ respondents (86/97) indicated that appropriate safeguards were implemented within their facilities for the safe return of hazardous drugs from patient care areas. Forty (41.2\%) of 97 respondents indicated that nonhazardous products were prepared in the same aseptic preparation areas as hazardous drugs. Of these, 20 (50\%) indicated that the same equipment (e.g., laminar airflow hood) was used to prepare hazardous drugs and other products.

\section{DISCUSSION}

The results of this survey, as reported here and in part 1 of this series, ${ }^{4}$ indicate a substantial degree of noncompliance with both CSHP guidelines and USP standards regarding the preparation of compounded sterile products in Canadian hospital pharmacies. Deficiencies were most notable in the areas of facilities and equipment, process validation, and product testing and release. Less than one-quarter of respondents reported the presence of a clean room meeting or exceeding the criteria for ISO class 8 in central pharmacy areas, which is a recommendation of both the CSHP and the USP. However, only one-quarter of respondents who reported environmental monitoring for particulate matter and microorganisms in the sterile preparation areas of their facilities also reported the presence of clean rooms with ISO class 8 air quality. Since environmental monitoring is a requirement for ISO air quality and clean room certification, ${ }^{12}$ these results bring into question the number of facilities that do, in fact, have legitimate clean room facilities. Similarly, a large number of respondents reported a lack of humidity control in their clean rooms, despite the necessity of this feature for clean room certification. $^{2}$

Both the CSHP guidelines and the chapter <797> standards give considerable attention to clean room facilities. As such, the scarcity of clean rooms among hospitals that responded to this survey is somewhat troubling. The apparent superficial knowledge of clean room standards may point to a lack of overall attention to, or knowledge of, the CSHP guidelines and USP standards among the survey respondents. The lack of clean room facilities implied by the results of this study may be a result of many factors, such as lack of familiarity with recommendations and standards, insufficient physical space in pharmacy areas, or budgetary limitations. According to one estimate, the renovations required to comply with USP standards may cost an organization more than US\$1 million. ${ }^{13}$ Although many organizations in the United States have acquired funding to build clean room facilities because the chapter $<797>$ requirements are now enforceable, Canada's current voluntary guidelines may be insufficient to compel organizations in this country to build the required facilities. 
More than $10 \%$ of respondents $(13.5 \%$ of those reporting on central pharmacies and $11.1 \%$ of those reporting on oncology IV prep areas) reported using only a "clean surface" (i.e., countertop) for compounding of sterile products. This is generally an undesirable practice, particularly for hazardous products such as antineoplastics. Also, more than half of respondents reported the presence of sinks and drains in aseptic preparation areas, and few had policies and procedures regarding their use. These results are troubling, as sinks and drains may be a source of bacterial or fungal growth, which could increase the risk of microbial contamination of sterile products prepared at these sites. More than one-quarter of respondents reported that the walls and ceilings in aseptic preparation areas were not cleaned on any regular basis, about $5 \%$ of respondents reported never cleaning or sanitizing their laminar airflow hoods after turning on these units, and barely more than half of respondents reported cleaning the hood between product sequences. Many respondents reported no calibration or certification of accuracy of automated compounding devices. It has also been reported that many facilities in the United States are not compliant with this recommendation. ${ }^{3}$

Only a small number of respondents reported testing products for pyrogens, and only $19.2 \%$ reported routine sterility testing. Roughly half of the respondents who reported that their facilities conducted pyrogenicity testing and sterility testing indicated elsewhere in the survey that their facilities used nonsterile raw materials in compounding sterile products. Sterility testing is strongly recommended for products prepared from nonsterile raw materials but is also recommended in association with other processes, such as preparation of batch products. The relative lack of sterility testing reported by the survey respondents raises concerns over the safety of these products. More than half of the respondents who reported sterility testing of batch products indicated that the products were not quarantined pending test results. This raises concerns about the utility of the testing done at these sites. If products are not quarantined pending the results of sterility testing, a product batch that ultimately fails testing may be administered to patients before the failure is revealed.

The expiry-dating practices reported by the respondents to this survey were often noncompliant with USP <797> standards (as outlined in Appendix 1). It should also be noted that the USP <797> expiry dates assume that the facility preparing a product is compliant with other USP <797> standards (e.g., those for clean rooms and other equipment). Given that many of the responding institutions were noncompliant in these areas, it can be argued that more conservative (i.e., shorter) expiry dating should be used in most Canadian hospitals. This would, however, have significant implications for the batching and centralization practices of many hospitals and health regions.

A substantial number of respondents indicated that records of original prescriptions, worksheets for batch products, documentation of complaints, recalls, and returns, and documentation of refrigerator and freezer temperature checks were not kept, contrary to the CSHP guidelines. A greater awareness of recommendations pertaining to record-keeping may help to increase the number of facilities that maintain adequate sterile compounding records.

In spite of widespread noncompliance with some recommendations and standards, there were a number of other areas in which the majority of respondents reported reasonable compliance with recommendations, including policies and procedures, storage and handling of sterile products, garbing, aseptic technique, and handling of hazardous products. Although there was, in general, a very high level of compliance with most recommendations related to policies and procedures, relatively few sites had policies and procedures for process validation and end-product testing and release. This may be related to the fact that only a small number of respondents reported the conduct of process validation and end-product testing at their sites. In addition, only a relatively small number of respondents reported the presence of a formal system to monitor, evaluate, correct, and improve sterile compounding practices. This reflects the apparent overall lack of attention to the monitoring and evaluation of sterile-product compounding activities by the hospitals represented in this survey.

Not surprisingly, the areas for which a large majority of respondents reported a high degree of compliance with recommendations were generally those for which the greatest number of facilities had policies and procedures. An important exception, the area of facilities and equipment, may not have benefited as readily from policies and procedures because of the difficulties involved in building and maintaining the facilities required to meet recommendations. There was generally a high level of compliance with most recommendations regarding garb, with the exception of makeup restrictions, leg coverings, and eye protection. These results contrast with the findings of Morris and others, ${ }^{14}$ who reported low levels of compliance with garbing recommendations in US hospitals.

The results of this survey revealed that compliance with a wide variety of recommendations and standards was substantially lower in satellite pharmacies than in other pharmacy areas. This may be due to several factors, such as the physical space and budgetary limitations that may apply in satellite pharmacies. However, without data on the proportion of sterile products that are produced in satellite pharmacies relative to central IV admixture areas, it is difficult to gauge the significance of this problem.

About one-half of respondents reported formal training of pharmacists in sterile compounding practices and procedures, similar to the 1993 finding that $60.5 \%$ of Canadian hospitals provided formal training to pharmacists. ${ }^{15}$ Nearly all respondents in the current study reported formal training of technicians, whereas only $44.0 \%$ of Canadian hospitals formally trained technicians in sterile compounding in the earlier study. ${ }^{15}$ Consistent with the increase in formal training 
of technicians, pharmacists are now less commonly involved in routine sterile compounding than in the earlier study $(17.8 \%$ and $68.5 \%$, respectively), and more sites now allow pharmacy technicians to compound sterile products without limitations ( $72.9 \%$ and $53.4 \%$, respectively). Further supporting this trend toward greater technician involvement and independence in sterile compounding was the finding that more than half of the facilities represented in this survey used technicians to check products following preparation. Of note, $18 \%$ of these respondents did not indicate any pharmacist involvement with product checking, which implies that technicians alone were responsible for product checking.

In addition to the items noted above, this study demonstrated substantial improvements over the 1993 study in a number of areas. ${ }^{15}$ For instance, a greater proportion of respondents in this study reported that the floors in the aseptic preparation area were cleaned every day $(75.0 \%$ versus $44.4 \%)$. There was also a shift to retaining multiple-dose vials for shorter periods: Fitch and Hall ${ }^{14}$ reported that $27.0 \%$ of sites kept multiple-dose vials for 30 days following initial use and that $26.0 \%$ of sites discarded them only after the manufacturer's expiry date, whereas $65.7 \%$ of respondents to the current survey reported keeping multiple-dose vials for only 2-29 days (with refrigeration) before discarding. Single-use vials are now discarded after a single use at $61.6 \%$ of sites, whereas only $41.5 \%$ reported following this practice in the 1993 study. ${ }^{15}$ Temperature checks of refrigerators and freezers were conducted daily at $45.1 \%$ of sites in the 1993 study; now, the percentage is $81.6 \%$.

In spite of these improvements, many areas have seen little or no improvement since the earlier study. For example, there has been little improvement in the prevalence of written policies and procedures relating to sterile compounding. A total of $88.7 \%$ of respondents to this survey had written policies and procedures regarding sterile product preparation, compared to $84.0 \%$ of sites in the 1993 study. Similarly, $71.6 \%$ of sites in this survey reported that their policies and procedures were updated less frequently than every 2 years, whereas $79.1 \%$ of hospitals surveyed in 1993 indicated that their sterile compounding policies and procedures were updated every 1 to 2 years. As noted previously, the amount of formal training in sterile compounding for pharmacists has decreased since the previous study, probably because of greater technician involvement and independence in this area. Annual refresher courses were reportedly offered by roughly one-third of hospitals in the 1993 study; now, roughly half of sites offer such courses. Sterility testing of compounded sterile products was conducted by only $19.2 \%$ of sites in this study, whereas $23.0 \%$ of sites in the previous study reported testing the sterility of products for immediate use, and $38.1 \%$ reported testing the sterility of batch lots.

This study had a number of limitations. The data obtained through the survey were self-reported and were not verified by objective observation. As such, a Hawthorne-type effect (i.e., an effect on study participants of the knowledge that they were being studied) may have skewed the results. The method of dissemination of the survey might have led to some selection bias, as some facilities might have been missed in the initial mailing, and some directors of pharmacy might have neglected to provide the investigators with the e-mail addresses of pharmacy managers within their jurisdictions. The survey was relatively long, which could have affected the accuracy of some of the results (e.g., respondents may have hurried to complete as many questions as possible before abandoning the task). Finally, different respondents may have interpreted certain questions differently, leading to inconsistent responses and reducing accuracy.

Despite a growing awareness of the importance of good sterile compounding practices, there remains a troubling disconnect between current Canadian and US standards of practice in this area and the actual practices of Canadian hospital pharmacies. As noted previously, the construction and maintenance of a certified clean room may be prohibitively expensive for many organizations, and the voluntary nature of current Canadian guidelines may be insufficient to initiate change in this area. Although it has been pointed out that chapter $<797>$ has been enforced very little since its introduction, ${ }^{13}$ the possibility that it may be strictly enforced by accreditation organizations may be enough to motivate change in US health care facilities. The CSHP guidelines often lack specificity, which may impede the development and implementation of the practices required to comply with recommendations. All of this raises the question of whether meaningful improvement will occur in Canada without the development, by the responsible regulatory authorities, of enforceable standards governing the compounding and use of sterile products.

\section{References}

1. Guidelines for preparation of sterile products in pharmacies. Ottawa $(\mathrm{ON})$ : Canadian Society of Hospital Pharmacists; 1996 [cited 2006 Nov 7]. Available from: http://www.cshp.ca/dms/dmsView/1_15-Sterileproducts.pdf [membership required to access content]

2. Pharmaceutical compounding-sterile preparations (general chapter 797). In: United States Pharmacopeia 27- National Formulary 22. Rockville (MD): United States Pharmacopeial Convention; 2004. p 2350-2370.

3. Candy TA, Schneider PJ, Pedersen CA. Impact of United States Pharmacopeia chapter 797: results of a national survey. Am J Health Syst Pharm 2006;63(14):1336-1343.

4. Warner T, Nishi C, Checkowski R, Hall KW. Survey of sterile admixture practices in Canadian hospital pharmacies: part 1. Methods and results. Can J Hosp Pharm 2009;62(2):100-111.

5. American Society of Health-System Pharmacists. ASHP technical assistance bulletin on quality assurance for pharmacy-prepared sterile products. Am J Health Syst Pharm 1993;50(11):2386-2398.

6. American Society of Health-System Pharmacists. ASHP guidelines on quality assurance of pharmacy-prepared sterile products. Am J Health Syst Pharm 2000;57(12):1150-1169.

7. ASHP self-assessment tool for compounding sterile preparations: an online primer for determining compliance with USP chapter $<797>$. Bethesda (MD): American Society of Health-System Pharmacists; [cited 2006 Nov 6]. Available from: http://www.ashp.org/emplibrary/ SAT-PrintableSurvey.pdf 
8. Federal standard 209E: Airborne particulate cleanliness classes in cleanrooms and clean zones. Mount Prospect (IL): Institute of Environmental Sciences; rev 1992 [cited 2009 Mar 24]. Available: http://www.set3.com/papers/209e.pdf

9. ISO 14644-1: Cleanrooms and associated controlled environments- Part 1. Classification of air cleanliness. Geneva (Switzerland): International Organization for Standardization; 1999.

10. Kastango ES. ASHP discussion guide for compounding sterile preparations: summary and implementation of USP chapter <797>. Bethesda (MD): American Society of Health-System Pharmacists; 2008.

11. Guidelines for handling and disposal of hazardous pharmaceuticals (including cytoxic drugs). Ottawa $(\mathrm{ON})$ : Canadian Society of Hospital Pharmacists; 1997 [cited 2006 Nov 7]. Available from: http:// www.cshp.ca/dms/dmsView/ 1_1_1_06-Disposal-o.hazardous-pha.pdf

12. FS 209E and ISO 14644 cleanroom classification standards. Pacific Scientific Instruments; [cited 2007 Feb 25]. Available from: http:// www. particle.com/whitepapers_met/cleanroom $\% 20$ standards.htm\#Contents

13. Thompson CA. USP chapter 797 enforceable but not often enforced. Am J Health Syst Pharm 2006;63(11):988,990.

14. Morris AM, Schneider PJ, Pedersen CA, Mirtallo JM. National survey of quality assurance activities for pharmacy-compounded sterile preparations. Am J Health Syst Pharm 2003;60(24):2567-2576.

15. Fitch DP, Hall KW. Survey of sterile product compounding practices in Canadian hospital pharmacies. Can J Hosp Pharm 1993;46(6):249-260.
Travis Warner, BSP, ACPR, is a Staff Pharmacist with St. Boniface General Hospital, Winnipeg, Manitoba.

Cesilia Nishi, BSCPharm, ACPR, is a Staff Pharmacist with the Winnipeg Regional Health Authority, Winnipeg, Manitoba.

Ryan Checkowski, BSCPharm, ACPR, is a Staff Pharmacist with the Winnipeg Regional Health Authority, Winnipeg, Manitoba.

Kevin W Hall, BScPharm, PharmD, is the Regional Director of Pharmacy, Winnipeg Regional Health Authority, Winnipeg, Manitoba.

\section{Address correspondence to:}

Dr Kevin W Hall

Regional Director of Pharmacy

Winnipeg Regional Health Authority

clo Deer Lodge Centre

North Pavilion, 2nd Floor

2109 Portage Avenue

Winnipeg MB

R3J OL3

\section{Acknowledgments}

Funding for the costs of conducting this study was provided by the Winnipeg Regional Health Authority. The Canadian Society of Hospital Pharmacists also provided support through electronic distribution of the survey, covering letter, and reminder notices.

\section{Appendix 1. Compounding Conditions and Associated Risk Levels ${ }^{210}$}

\section{Definitions of Risk Levels}

\section{Risk Level}

Low risk

\section{Characteristics of Preparation}

Compounded entirely under ISO class $5^{9}$ (Federal Standard 209E class $100^{8}$ ) conditions

Compounding involves only transfer, measuring, and mixing manipulations with closed or sealed packaging systems; performed promptly and attentively

Manipulations limited to aseptically opening ampoules, penetrating sterile stoppers on vials with sterile needles and syringes, and transferring sterile liquids in sterile syringes to sterile administration devices and packages of other sterile products

Medium risk Same conditions as those for low-risk level, with the following additional criteria:

Multiple individual or small doses of sterile products combined or pooled to prepare a compounded sterile product that will be administered either to multiple patients or to one patient on multiple occasions Compounding process includes complex aseptic manipulations other than the single-volume transfer Compounding process requires unusually long duration

The sterile compounded sterile products do not contain broad-spectrum bacteriostatic substances and are administered over several days

High risk Nonsterile ingredients are incorporated or a nonsterile device is employed before terminal sterilization Sterile ingredients, components, devices, and mixtures are exposed to air quality inferior to ISO class $5^{9}$ (Federal Standard 209E class 100)

Nonsterile preparations are exposed for at least $6 \mathrm{~h}$ before being sterilized

It is assumed that the chemical purity and content strength of ingredients meet their original and compendial specifications in unopened packages of bulk ingredients

ISO = International Organization for Standardization.

Beyond-Use Dating Based on Risk Level and Temperature

\begin{tabular}{lccc} 
Temperature & $\begin{array}{c}\text { Low-Risk } \\
\text { Preparation }\end{array}$ & $\begin{array}{c}\text { Medium-Risk } \\
\text { Preparation }\end{array}$ & $\begin{array}{c}\text { High-Risk } \\
\text { Preparation }\end{array}$ \\
\hline Controlled room temperature & $48 \mathrm{~h}$ & $30 \mathrm{~h}$ & $24 \mathrm{~h}$ \\
\hline $\begin{array}{l}\text { Cold temperature } \\
\left.\text { (refrigeration, } 2^{\circ} \mathrm{C} \text { to } 8^{\circ} \mathrm{C}\right)\end{array}$ & $14 \mathrm{~d}$ & $7 \mathrm{~d}$ & $3 \mathrm{~d}$ \\
\hline $\begin{array}{l}\text { Solid frozen state } \\
\left(-20^{\circ} \mathrm{C} \text { or below) }\right.\end{array}$ & $45 \mathrm{~d}$ & $45 \mathrm{~d}$ & $45 \mathrm{~d}$ \\
\hline
\end{tabular}

